
101(11), 1883

\author{
Postprint version : \\ Journal website \\ : https://www.sciencedirect.com/science/article/pii/S0738399118306888 \\ ?via\%3Dihub \\ Pubmed link $\quad:$ https://www.ncbi.nlm.nih.gov/pubmed/30301535 \\ DOI \\ : 10.1016/j.pec.2018.09.003
}

This is a Nivel certified Post Print, more info at nivel.nl

\title{
Bringing patient-centered innovation to Patient Education \& Counseling
}

\author{
Gregory Makoul*, Sara Rubinelli, Sandra van Dulmen, Xinchun (Angela) Liu, \\ John Vozenilek, Angela Zambeaux
}

Corresponding author at: Patient Wisdom Inc, 770 Chapel Street, Floor 1, New Haven, CT, 06510 E-mail address: gmakoul@patientwisdom.com (G. Makoul).

Patient Education \& Counseling (PEC) became the leading international journal for communication in healthcare by evolving to attract authors and readers interested in practical application of theorydriven research, reviews, and reflective practice. We are delighted to announce a new dimension in the evolution of PEC:

Patient-Centered Innovation will be an online special feature, tightly integrated with PEC, that focuses on work that brings patient perspectives into the design, implementation, and evaluation of interventions intended to improve health and transform health care delivery. As part of PEC, articles in Patient-Centered Innovation will be indexed in Medline/PubMed and carry the PEC impact factor. Innovation requires ideas and execution: It involves a disciplined process of defining problems to be solved, developing solutions for transformational change, implementing solutions, and measuring impact. Ideally, patient-centered innovation embraces patient perspectives in problem definition and solution design, and measures impact in terms of outcomes that matter to patients. The scope includes the full range of communication in terms of interpersonal, group, mediated, and technologyenabled innovations and interventions. In other words, innovation can be "low tech" as well as digital. By focusing on user-centered design and innovation with practical value, Patient-Centered Innovation aims to advance the pace and sustainability of meaningful change in areas such as care coordination; communication; health care encounters; medical and health professional education; patient experience; patient, family, caregiver, and community engagement; patient involvement; patientreported outcomes; relationship-centered care; remote monitoring; resilience; self-care; shared decision making; telehealth; and virtual access.

The editorial process will assess scientific quality of the work as well as efforts to ensure relevance and utility to patients and health professionals in real-world settings; we aim to partner with patients in this process. In addition to empirical studies on the process and outcome of patient-centered innovation, thoughtful articles on innovation design and development, innovation capacity and 
Makoul, G., Rubinelli, S., Dulmen, S. van, Liu, X.A., Vozennilek, J., Zambeaux, A. Bringing patientcentered innovation to Patient Education \& Counseling. Patient Education and Counseling: 2018, 101(11), 1883

sustainability, patient-centered research design, feasibility studies, and/or negative findings are welcome, as they can be instructive for others in the field.

As a concept, Patient-Centered Innovation may sound as simple and straightforward as PatientCentered Care. But simple things are hard in the context of everyday life and practice. The editorial team wants "patient-centered" to be more than a label, and will prioritize work that is truly patientcentered in the sense that patients are authentically involved in defining problems to be solved, designing potential solutions, and/or evaluating value. We look forward to working with the patient, provider, and innovation community to build a dynamic knowledge base focused on transformative work at the nexus of communication, health, and care. 